\title{
Una aproximación a la imagen del Sur en las revistas de Acción contra el Hambre y Oxfam Intermón
}

\section{Hegoaldeak Acción contra el Hambre eta Oxfam Intermón aldizkarietan duen irudia}

\section{An approach to the image of the Southern countries in the magazines of Action against Hunger and Oxfam Intermón}

\section{Laura Ibáñez Castejón 1}

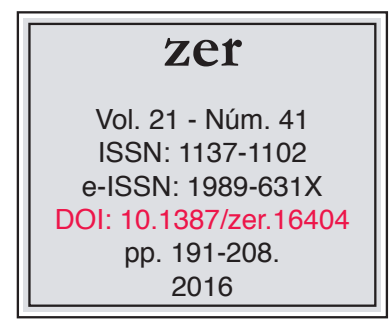

Recibido el 4 de marzo de 2016, aceptado el 28 de septiembre de 2016.

\section{Resumen}

Las ONGD de Desarrollo (ONGD) emplean la comunicación para transmitir su misión y para sensibilizar e involucrar al Norte en la resolución de los problemas del Sur. Para ello, difunden una determinada imagen sobre sus habitantes. En el estudio, se examina dicha imagen en las portadas de las revistas de Acción contra el Hambre y Oxfam Intermón, empleando el modelo de Van Leeuwen (2008). Como conclusión, se observa que las portadas refuerzan la dicotomía entre un Sur necesitado de ayuda y un Norte presto a ofrecérsela, siempre con la intermediación de las ONGD.

Palabras clave: ONG, desarrollo, fotografía, revista, discurso, ideología, análisis del discurso.

\section{Laburpena}

Garapenerako GKEek (GGKE) komunikazioa erabiltzen dute beren eginkizuna zein den helarazteko, eta Iparraldea Hegoaldeko arazoen inguruan sentsibilizatzeko eta arazo horiek konpontzera bultzatzeko. Horretarako, bertako biztanleen irudi jakin bat zabaltzen dute. Azterketan, Acción contra el Hambre eta Oxfam Intermon erakundeen aldizkarien azalak erabiltzen dira irudi hori aztertzeko. Ondorio gisa, ikusten da azalek honako hau erakusten

\footnotetext{
Universitat Autònoma de Barcelona. laura.ibanez@uab.cat
} 
dutela: laguntza behar duen Hegoaldea, eta laguntza hori emateko prest dagoen Iparraldea, beti GGKEen bitartekaritzaren bidez.

Gako-hitzak: GKE, garapena, argazkilaritza, aldizkaria, diskurtsoa, ideologia, diskurtsoaren analista.

\section{Abstract}

The NGOs on Development (NGOD) use different means of communication to transmit their main objective. Their mission is to engage the Northern countries in solving the problems of the South. As such, they try to transmit a particular image of its inhabitants. In this paper, we examine this image on the covers of the magazines Action against Hunger and Oxfam Intermón. We have used the method of Van Leeuwen (2008). In conclusion, the covers reinforce the dichotomy between the South, who needs help, and the North, who wants to help, but always with the intermediation of a NGOD.

Key words: NGO, development, photography, magazine, discourse, ideology, discourse analysis. 


\section{Introducción}

Desde el final de la Segunda Guerra Mundial, el discurso del desarrollo ha marcado la imagen que Occidente posee sobre los países del Sur. El fin de esta contienda bélica trajo consigo una nueva reestructuración de la realidad geopolítica. Las colonias comenzaron a obtener la independencia con respecto a las metrópolis, de manera que el imperialismo dejó de ser un discurso apropiado para definir las relaciones establecidas entre estas últimas y las nuevas naciones. Este contexto fue propicio para el nacimiento y auge del discurso del desarrollo, necesario para precisar la nueva realidad internacional.

El concepto "desarrollo" hace alusión a un proceso de cambio orientado y controlado hacia la consecución de una serie de objetivos. Implica una transformación hacia un estado que se considera superior o, cuanto menos, más gratificante que el que se posee (Sevilla Guzmán, 2000). A través del discurso del desarrollo, se juzgó que el desarrollo propicio para todas las naciones era el que había acontecido en los países del Norte, obviando que éste era solo un desarrollo histórico geográficamente situado. Occidente se convirtió en el modelo a seguir y en la medida del progreso social para el resto del mundo. La civilización, la racionalidad y el progreso occidentales fueron proclamados como valores universales.

Es por ello que los teóricos del posdesarrollo (Viola, 2000; Esteva, 2000; Picas, 2001, 2003; Escobar, 2007, 2010, 2012) consideran que los conceptos "desarrollo" y "subdesarrollo" están atravesados de poder. El subdesarrollo aparece asociado a carencia de lo necesario o a una situación de insuficiencia, de inferioridad, que no se ha acabado de desarrollar. Por tanto, siempre lleva implícita la dicotomía entre desarrollo y subdesarrollo. Este último es construido e imaginado como una alteridad diferenciada que permite, a su vez, que Occidente se vea a sí mismo como su lado opuesto, la parte positiva de dicha dicotomía. Como explica Mohanty (2008: 159), "Solo es posible definir al 'Tercer Mundo' como subdesarrollado y económicamente dependiente desde el punto de vista privilegiado de Occidente. Sin el discurso sobredeterminado que crea el Tercer $M u n d o^{2}$, no habría un (singular y privilegiado) Primer Mundo". Por tanto, las nociones "desarrollo" y "subdesarrollo" son problemáticas para los/as investigadores/as del posdesarrollo pues ambos conceptos implican una misma manera de aproximarse a la realidad: una mirada condicionada por Occidente que se muestra incapaz de apreciar los diferentes valores, experiencias y conocimientos de cada cultura.

El discurso del desarrollo ha sufrido diversas modificaciones y críticas a lo largo del tiempo ${ }^{3}$. En la actualidad, el desarrollo se conceptualiza principalmente como desarrollo humano y sostenible ${ }^{4}$.

\footnotetext{
2 Cursiva de la autora.

3 Para una revisión sobre las distintas formas de entender el desarrollo, véase UNCETA, Koldo (2009). Desarrollo, subdesarrollo, maldesarrollo y posdesarrollo. Una mirada transdisciplinar sobre el debate y sus implicaciones. Carta latinoamericana. Contribuciones en desarrollo y sociedad en América Latina, $\mathrm{n}^{\circ}$ 7, pp. 1-34.

4 Tras finalizar el plazo de los Objetivos de Desarrollo del Milenio, en septiembre de 2015, se presentaron los Objetivos de Desarrollo Sostenible que estarán vigentes hasta 2030. Éstos no solo buscan que el desarrollo sea humano, sino que también ha de ser sostenible.
} 


\section{Las ONGD y la comunicación}

El discurso del desarrollo ha empleado la cooperación internacional como una nueva estrategia de la geopolítica mundial. Entre sus herramientas se hallan las ONG de Desarrollo (ONGD). Diversos/as autores/as han destacado la importancia de la comunicación para éstas (Martínez Sánchez, 1998; Gómez Gil, 2005; González Luis, 2006). Dado que son entidades privadas, han de recaudar fondos para realizar sus acciones. Así, se sirven de la comunicación para darse a conocer e informar a la ciudadanía sobre su misión. Además, como explica González Luis (2006), existen otras cuatro áreas donde la emplean: la información, que dan a los/as periodistas para que éstos la trasladen a la opinión pública y que las ONGD transmiten a través de sus blogs, redes sociales, etc.; la sensibilización y la educación para el desarrollo, que, con diferentes grados de profundidad y emotividad, pretenden concienciar a la ciudadanía del Norte sobre los problemas del Sur; y la labor de grupo de presión, que suponen un conjunto de acciones (diálogo, difusión de información, presión, etc.) que tienen como fin influir en diversos grupos sociales (entidades privadas, instituciones nacionales e internacionales) con capacidad para producir cambios.

Pero la comunicación no solo es importante en la medida en que sirve para que las ONGD puedan cumplir sus objetivos. Sus mensajes también contribuyen a formar en la opinión pública occidental una determinada imagen sobre los países del Sur, ya que, de acuerdo con Nos, Iranzo y Farné (2012: 214):

La forma en que las ideas y realidades sociales se representan influye en el modo en que las personas piensan en ellas, se relacionan con ellas y actúan en consecuencia. En otras palabras, la retórica está estrechamente vinculada al modo en que los públicos piensan sobre los temas y las personas de las que habla la comunicación de las ONGD, por lo que puede jugar un papel crucial en sus comportamientos.

Las ONGD contribuyen a formar la imagen del Sur de dos maneras fundamentalmente. En primer lugar, son fuentes de información para los medios de comunicación. Como revela una encuesta realizada a un conjunto de periodistas por la Coordinadora de ONG para el Desarrollo-España (CONGDE) $)^{5}$, el $73 \%$ de los/as profesionales encuestados se mostraba interesado/a en recibir información sobre estas entidades. Asimismo, el 90\% de ellos consideraba el grado de relevancia y de fiabilidad de las ONGD como bueno o muy bueno.

En segundo lugar, las ONGD también son productoras y difusoras de mensajes en los que aparecen las poblaciones del Sur. Muchas de estas entidades tienen páginas web, redes sociales o blogs, envían newsletter a sus seguidores/as y/o editan una publicación en papel accesible, en muchas ocasiones, también desde Internet. Es decir, pueden comunicarse directamente con la ciudadanía del Norte sin la necesidad de pasar por los filtros impuestos por los medios de comunicación.

5 Coordinadora de ONG para el Desarrollo-España (2007). Los medios de comunicación y las ONGD: Situación actual y retos. Recuperado de http://www.portalsida.org/repos/manualmed.pdf 
Actualmente, la proliferación de los actores humanitarios y de los soportes, los medios de comunicación y la tecnología capaz de transmitir información, el interés mediático surgido en torno a los desastres naturales así como la atención creciente centrada en diversos conflictos internacionales debido al nuevo contexto de seguridad internacional produce una sobrecarga de contenidos de corte humanitario (Ciancio, 2007). Así, el problema no reside en la falta de este tipo de información sino en su tratamiento. Diversos/as autores/as (Martínez Sánchez, 1998; López García, 2005; González Luis, 2006; Bernabé, 2007; Martín Nieto, 2009) han denunciado el hecho de que, en muchas ocasiones, este tipo de contenidos ha dado una imagen sobre el Sur negativa, pues lo han ligado a catástrofes y a situaciones de precariedad.

Según la encuesta anteriormente citada, el $81 \%$ de los temas relacionados con las ONGD que más se tratan en los medios de comunicación son las catástrofes humanitarias, según los/as informadores/as encuestados/as. Asimismo, cuando se habla de aspectos relacionados con la cooperación al desarrollo, los temas que más aparecen, con un $78 \%$, suelen ser las acciones humanitarias y las emergencias.

Por su parte, la comunicación de las ONGD también ha suscitado críticas. Como señala Martínez Sánchez (1998), éstas han primado una serie de mensajes con los que se ha buscado fundamentalmente captar fondos a corto plazo. Además, muchas de ellas han tenido que adaptarse a las lógicas de los medios de comunicación (Picas, 2003; Gómez Gil, 2005), que priman mensajes en los que sobresalen elementos espectaculares y sensacionales (Bourdieu, 1996). Todo ello ha conducido a las ONGD a dar, en ocasiones, imágenes sobre el Sur en exceso dramáticas ${ }^{6}$, algo que es más evidente cuando se produce una catástrofe. Relacionado con este hecho, la investigación de González Luis (2006), en la que se analizaban las notas de prensa difundidas por un grupo de ONGD así como las noticias de prensa en las que éstas aparecían, ha revelado que, en situaciones de normalidad, las ONGD tienden a difundir una imagen favorable sobre el Sur, destacando cualidades positivas como su fortaleza o su solidaridad. En cambio, cuando ocurre algún desastre, la imagen difundida es un tanto estereotipada, pues se caracteriza a los habitantes del Sur como víctimas, insolidarios y dependientes de los países ricos.

Dado que, como afirma Van Dijk (2009), la ciudadanía del Norte sobre todo conoce a las poblaciones del Sur a través de los mensajes difundidos en los medios de comunicación y puesto que las ONGD son actores fundamentales a la hora de hablar sobre estas últimas, resulta relevante conocer la imagen que difunden sobre ellas, puesto que dicha imagen condiciona las relaciones entre Norte y Sur y la forma en que el primero se involucra en los problemas del segundo.

\section{Metodología}

El objeto de estudio es el discurso de las ONGD sobre las poblaciones del Sur. Se ha analizado en las revistas de las ONGD Acción contra el Hambre y Oxfam Intermón

\footnotetext{
${ }_{6}$ No obstante, las ONGD que forman parte de la CONGD, han de respetar el Código de conducta sobre imágenes y mensajes a propósito del Tercer Mundo (disponible en http://acpp.com/acpp2/descargas/codigo_conducta_imagenes.pdf), por el que se han de evitar: las imágenes que generalizan y esconden la diversidad de las situaciones; las imágenes idílicas (que no presentan la realidad tal y como es verdaderamente, incluso si ésta no es siempre buena) o de 'aventuras' o exóticas; las imágenes acusadoras; las imágenes que subrayan la superioridad del Norte; y las imágenes que muestran de forma miserable o patética una situación.
} 
publicadas entre 2013 y 2015. El objetivo que se ha tratado de alcanzar es conocer el modo en el que aparecen representadas las personas del Sur en las imágenes de las publicaciones de las ONGD analizadas. Se ha buscado comprobar la siguiente hipótesis: las revistas de las ONGD muestran en sus fotografías a las personas del Sur como ajenas a la realidad de la ciudadanía del Norte, hecho que redunda en una construcción alteriza del Sur con respecto al Norte.

Para llevar a cabo la investigación, se recogieron 23 revistas publicadas por Acción contra el Hambre y Oxfam Intermón entre 2013 y 2015. Por tanto, el corpus está conformado por 23 revistas, 13 pertenecientes a la primera ONGD y 10 a la segunda.

De cada una de las revistas, tan solo se han examinado las portadas en las que aparecían personas, ya fueran éstas del Sur o del Norte. Es decir, la muestra está conformada por las portadas de las revistas de los números del $59^{7}$ al 71 de Acción contra el Hambre, exceptuando el número 61, ya que no aparecía ninguna figura humana, y las portadas de Oxfam Intermón del número $26^{8}$ al 35 . En total, 12 portadas de Acción contra el Hambre y 10 de Oxfam Intermón.

Se decidió escoger las portadas porque, en ellas, las fotografías son el elemento más destacado. Por tanto, son un buen medio para examinar la imagen que las ONGD dan sobre las poblaciones del Sur. De igual modo, la portada es como una suerte de escaparate de la publicación, la primera página que ve el público lector, de manera que debe ser atrayente y captar su atención. Puesto que ésta es la primera impresión que el público lector recibe sobre los contenidos que aparecen en la revista, la portada es una de las páginas más importantes de cualquier publicación. En periodismo, el diseño no solo cumple una función estética sino que también jerarquiza los contenidos. Así, en portada se recogen los contenidos que para quien edita la revista son más destacados. Este hecho significa que, mediante su examen, se puede conocer qué mensajes e imágenes quieren transmitir las ONGD en primer lugar a sus públicos.

Las siguientes imágenes recogen las portadas que se han analizado en la investigación:

Imagen 1. Portadas de 2013 de las revistas de Acción contra el Hambre (de izquierda a derecha: números $59,60,62$ y 63).

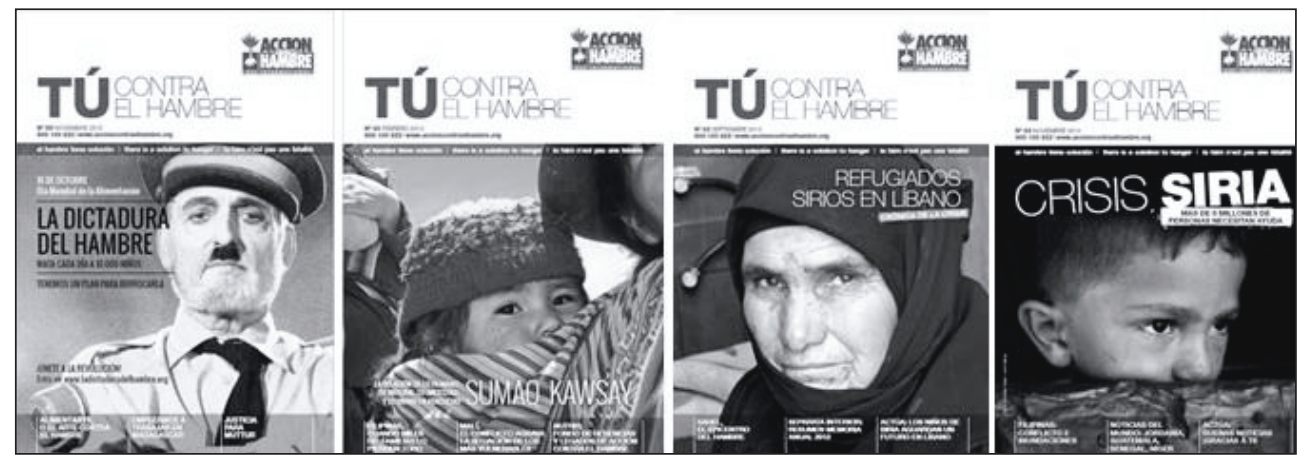

\footnotetext{
7 Aunque la revista se publicó en noviembre de 2012, se decidió incluirla en la investigación, ya que hasta febrero de 2013 no se editó el siguiente número de la publicación de Acción contra el Hambre.

8 A pesar de que la revista se publicó en diciembre de 2012, se ha incluido en el estudio, ya que estuvo vigente hasta mayo de 2013, mes en el que vio la luz el número 27.
} 
Imagen 2. Portadas de 2014 de las revistas de Acción contra el Hambre (de izquierda a derecha: números 64, 65, 66 y 67).

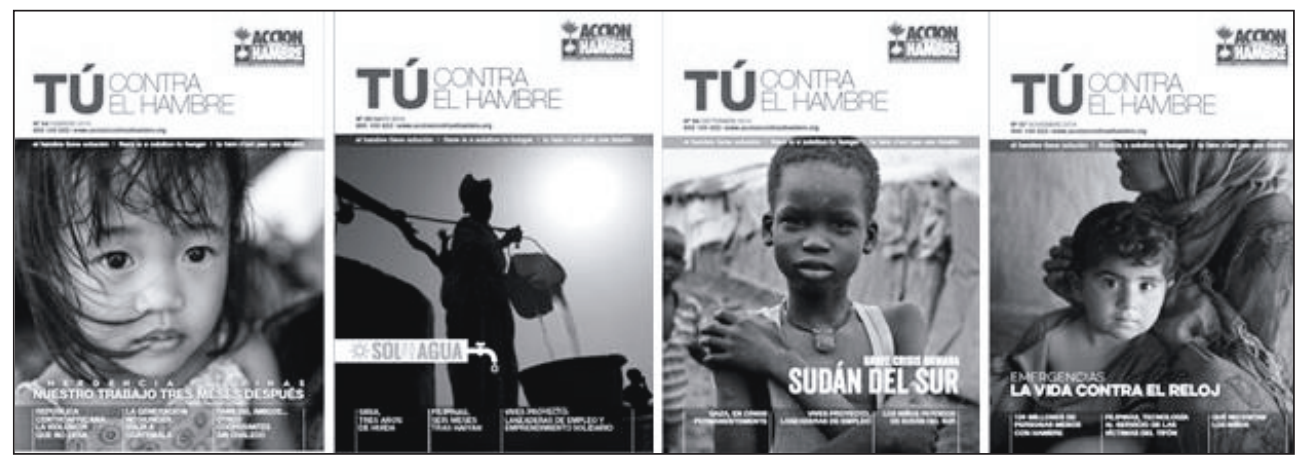

Imagen 3. Portadas de 2015 de las revistas de Acción contra el Hambre de izquierda a derecha: números 68, 69, 70 y 71).

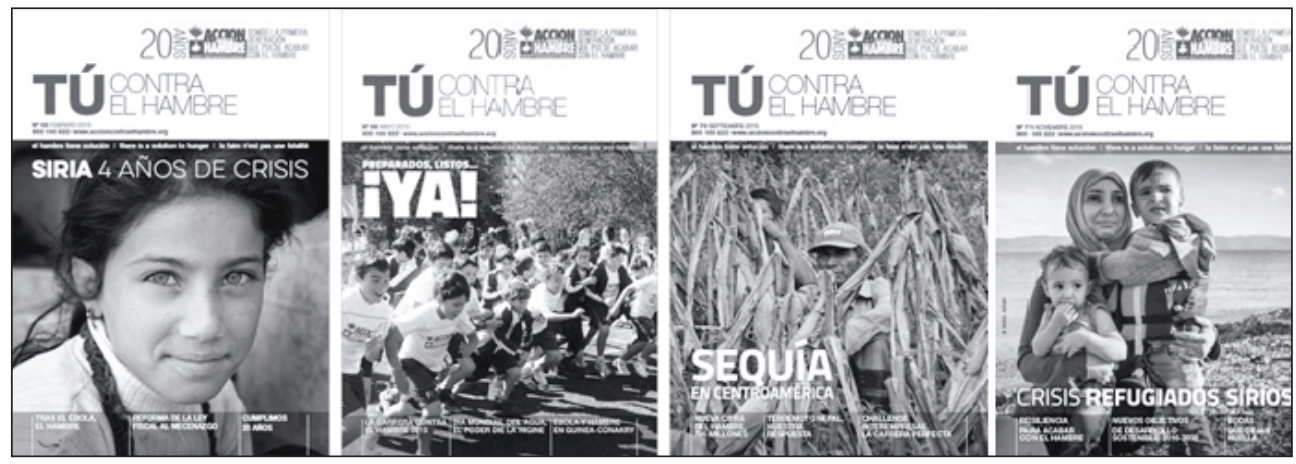

Imagen 4. Portadas de 2013 de las revistas de Oxfam Intermón ${ }^{9}$ (de izquierda a derecha: números 26, 27, 28 y 29).

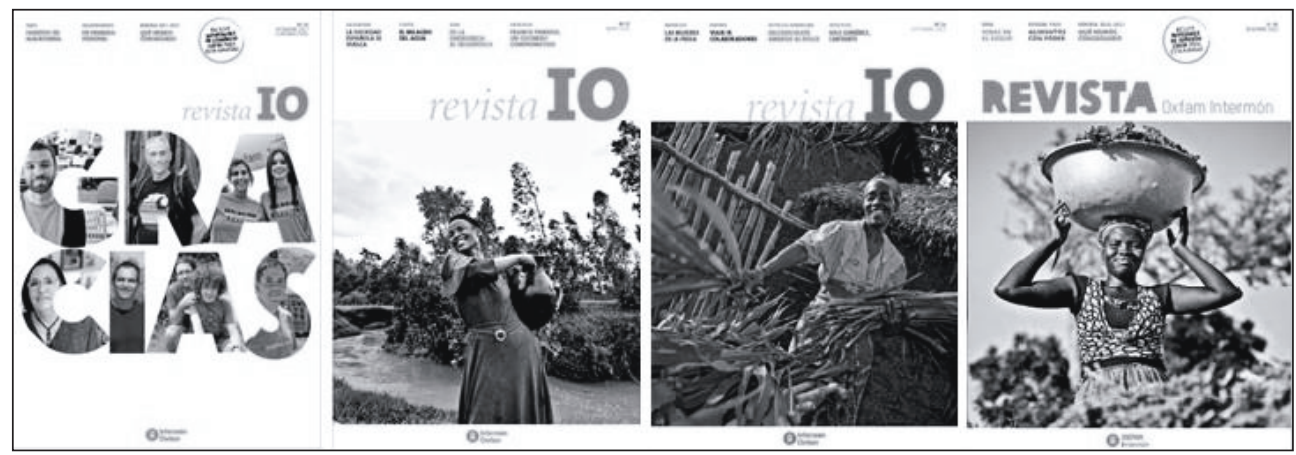

9 A partir del 15 de octubre de 2013 Intermón Oxfam pasó a denominarse Oxfam Intermón. Por eso, a partir del último número de 2013 el nombre de la revista varía. 
Imagen 5. Portadas de 2014 de las revistas de Oxfam Intermón (de izquierda a derecha: números 30,31 y 32 ).

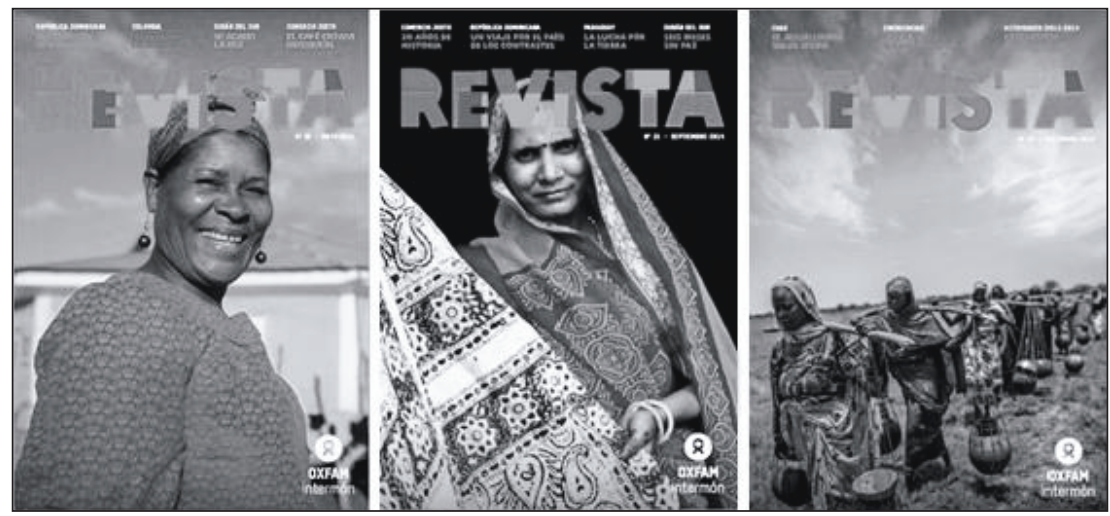

Imagen 6. Portadas de 2015 de las revistas de Oxfam Intermón (de izquierda a derecha: números 33, 34 y 35).
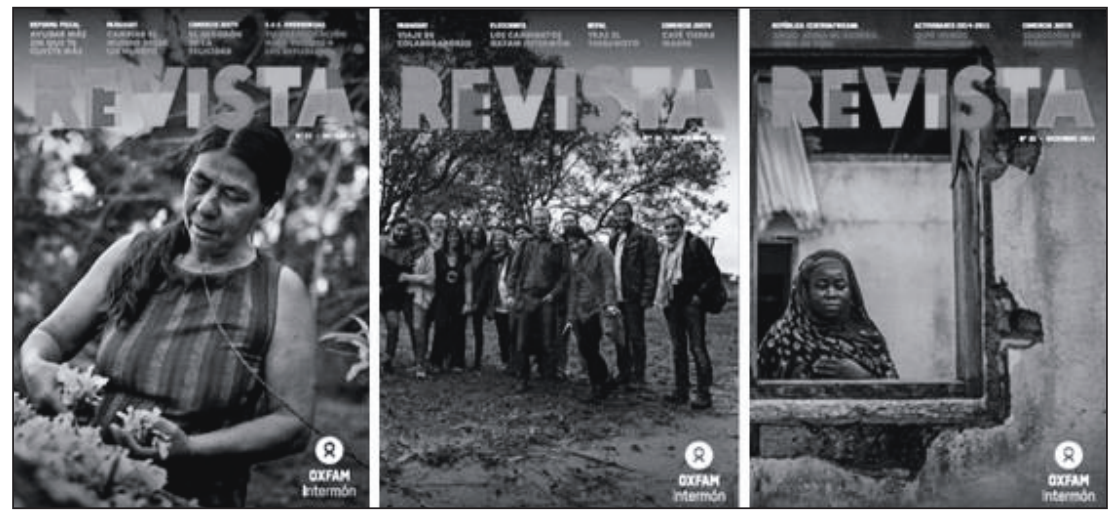

El interés por estudiar las revistas se debe a que éstas son elaboradas por el personal de las ONGD, por tanto, estas organizaciones poseen un gran control sobre ellas. Esto no ocurre, por ejemplo, cuando la ONGD es utilizada como fuente de información de una noticia, ya que, en este caso, es el/la periodista quien controla el resultado final. Además, estas publicaciones son recibidas por los/as socios/as y colaboradores/as de las ONGD con el objetivo de fidelizarlos. Es decir, las reciben personas que ya poseen un interés y una mayor sensibilización frente a las cuestiones relacionadas con el Sur. Esta predisposición así como la mayor extensión de las revistas frente a otro tipo de mensajes permite a la ONGD tratar con más profundidad dichas cuestiones. Asimismo, puesto que las revistas también se pueden visualizar en las páginas web de las ONGD contempladas en la investigación, su público potencial es mayor que sus socios/as y colaboradores/as ${ }^{10}$.

\footnotetext{
${ }^{10}$ En el caso de Oxfam Intermón, las revistas también se pueden conseguir en sus tiendas de comercio justo.
} 
Se decidió escoger Acción contra el Hambre y Oxfam Intermón por ser dos ONGD muy destacadas en el ámbito de la cooperación española. De acuerdo con los datos aportados por la encuesta que la CONGDE ha realizado a 74 de sus 80 organizaciones ${ }^{11}$, Acción contra el Hambre es la organización que más fondos recibe de su base social, compuesta por particulares y entidades privadas, periódicamente y la primera con más fondos, siendo la ONGD que percibe más fondos públicos. Oxfam Intermón es la segunda organización que más fondos recoge de su base social periódica y la segunda con más fondos. Es la entidad que más fondos recibe de manos privadas. También es interesante destacar que Oxfam Intermón y Acción contra el Hambre son la primera y la segunda de las entidades encuestadas con más personal local respectivamente.

Se eligieron también estas dos organizaciones debido a que poseen perfiles un tanto diferentes. Así, Acción contra el Hambre es una organización principalmente de ayuda humanitaria, siendo la organización que más fondos dedica a esta labor de todas las encuestadas. Sin embargo, Oxfam Intermón está más especializada en la cooperación al desarrollo. Es la entidad encuestada que más fondos destina a esta partida. No obstante, esta última ONGD también se dedica a la acción humanitaria, siendo la segunda que más fondos emplea para esta labor.

El estudio se encuadra dentro del Análisis Crítico del Discurso (ACD). Las investigaciones llevadas a cabo dentro de este campo se centran "on the role of discourse in the (re)production and challenge of dominance" (Van Dijk, 1993). En el caso del desarrollo, pensarlo "en término de discurso permite concentrarse en la dominación -como lo hacían, por ejemplo, los primeros análisis marxistas- y, a la vez, explorar más productivamente las condiciones de posibilidad y los efectos más penetrantes del desarrollo" (Escobar, 2007: 23). Es por ello que, en este trabajo, se ha optado por estudiar el modo en que las ONGD presentan a las poblaciones del Sur en sus revistas de manera discursiva, como una parte del discurso del desarrollo. Con este objetivo, se ha empleado una metodología crítica, el ACD, que permite desentrañar las relaciones de dominación dentro de un determinado discurso.

Distintos/as autores/as han barajado diversos modos y herramientas para llevar a cabo sus análisis del discurso dentro del ACD (para una aproximación a distintas variantes del ACD, véase Wodak y Meyer, 2003; Hidalgo Tenorio, 2011; Wodak, 2011). En el presente estudio, se ha realizado un ACD de corte multimodal. Es decir, se han considerado las revistas de las ONGD como textos multimodales, ya que, en ellas, se combinan distintos recursos, como son, en este caso, las imágenes y la palabra escrita, para comunicar un determinado mensaje. En concreto, se ha seguido el modelo propuesto por Van Leeuwen (2008) para estudiar la representación visual de las actoras y de los actores sociales. Para completarlo, se han tomado también algunas indicaciones de Kress y Van Leeuwen (2006).

Como indica Van Leeuwen (2008), a través de las fotografías, se establece, a nivel simbólico, una relación interpersonal entre quien aparece en ellas y quien las mira. Dicha relación viene marcada por tres dimensiones: la distancia social, la relación social y la interacción social. La distancia social queda reflejada mediante el uso

\footnotetext{
${ }^{11}$ Coordinadora de ONG para el Desarrollo-España (2013). Informe 2014. Recuperado de http://informe2014.coordinadoraongd.org/descargas/datos. Los datos de esta encuesta, referidos al año 2013, son los más recientes aportados por la CONGDE.
} 
de los planos: cuando las personas son mostradas en planos cercanos, se las retrata como si fueran próximas a quien las observa mientras que cuando se usan planos lejanos, se las presenta como alejadas de la realidad de quienes miran la imagen. A efectos de este estudio, se han considerado planos cercanos desde los primeras planos hasta los planos medios, es decir, imágenes que muestran a la persona hasta la altura de su cintura. Se estableció que eran planos alejados aquéllos que recogían a las personas más allá de sus rodillas (planos americanos y planos generales).

En cuanto a la relación social, ésta se expresa a través del ángulo. Así, siguiendo el eje vertical, los ángulos que se ubican a la altura de los ojos de la persona retratada marcan una relación de igualdad entre ésta y quien observa la imagen. Los ángulos picados y contrapicados simbolizan relaciones de poder desigual entre quien es representado y quien observa la imagen. En el primer tipo de ángulos, se da poder a quien mira la imagen frente a quien aparece en ella mientras que en los contrapicados el sujeto representado en la fotografía posee cierto poder frente a quien le observa. En esta investigación, se ha considerado que los ángulos que representan con un carácter más positivo a las personas del Sur son aquéllos que se ubican a la altura de los ojos y los contrapicados.

Con respecto a los ángulos en el eje horizontal, Kress y Van Leeuwen (2006) efectúan una distinción entre aquéllos que muestran a la persona frontalmente y aquéllos que la captan oblicuamente. Mientras que los primeros incluyen, de manera simbólica, a quien mira la imagen en el universo de la persona representada, los segundos indican que dicho universo es ajeno a quien observa la fotografía.

La última dimensión propuesta por Van Leeuwen (2008) establece si existe interacción entre la persona representada y quien mira la imagen. En el caso de que la persona mostrada en la fotografía mire a la cámara o se dirija a ella mediante gestos, de manera simbólica, demanda algo a quien la observa. Por el contrario, cuando la persona representada no se dirige a quien la mira, se ofrece como un objeto para la contemplación. A efectos de esta investigación, se han considerado más positivas las imágenes en las que se establece interacción entre las dos partes.

Sin embargo, es preciso decir que estas dimensiones pueden combinarse de distinta manera en una misma imagen. De este modo, una de ellas puede apuntar hacia un sentido y otra hacia su opuesto. En palabras de Van Leeuwen (2008: 141):

The gradations and multiple combinations these dimensions allow can realize many different ways of depicting people as 'others'. The same image parameters can be used to show the exclusion, the keeping-at-a-distance of people, in order to accuse and critique, or to ourselves exclude and keep at a distance members of our own school class, our own community, or own country, etc.

El otro aspecto que se ha tenido en cuenta para conocer cómo se presentan a las personas del Sur ha sido el tipo de caracterización que se ha empleado. En un primer momento, cuando se observa una imagen, se ha de reflexionar sobre la posibilidad de que haya personas excluidas en la representación. Es cierto que el hecho de que un 
colectivo no aparezca en las imágenes puede tratase de una exclusión puntual, pero si ésta se repite en numerosas ocasiones, se le puede estar invisibilizando.

El siguiente aspecto analizado ha sido el rol. Así, el sujeto puede aparecer envuelto en una acción, es decir, como agente, o de manera pasiva, sin llevar a cabo ninguna actividad. En el caso de que se lo presente de manera activa también se ha de observar el rol que desempeña, pues la representación puede asociar simbólicamente ciertos roles con algún colectivo específico. Éste podría ser el caso, por ejemplo, de asociar a las mujeres con roles reproductivos relativos al hogar y la maternidad.

Otro aspecto examinado ha sido si se ha representado a la persona de manera específica o genérica. En el primer caso, se resaltan las características que se consideran propias de la persona representada. En cuanto al segundo tipo de caracterización, se trata de un tipo de representación más estereotipada, puesto que se destacan los rasgos que se consideran propios del grupo social con el que se asocia al sujeto retratado. En este tipo de caracterización, se puede representar a las personas, por ejemplo, con una determinada vestimenta o un determinado peinado. Es necesario aclarar que las características resaltadas poseen un valor determinado (positivo o negativo) dado por la cultura que recibe la imagen.

Si se hace una caracterización genérica, se puede categorizar a las personas en función de rasgos de corte biológico o cultural (o una combinación de ambos). En el primer caso, se resaltan rasgos físicos de la persona representada mientras que, en el segundo, caso, la representación destaca elementos como, por ejemplo, la vestimenta o el peinado.

Por último, se puede representar a las personas individualmente o en grupo. Si se hace en grupo, se puede retratar a los sujetos diferenciadamente, es decir, de manera que se destaque cada uno de ellos en el conjunto de la composición, o de manera homogeneizada, creando la sensación de que todas las personas representadas son similares.

Al igual que ocurre con las dimensiones que marcan la relación interpersonal establecida a través de las imágenes a nivel simbólico, los distintos aspectos relacionados con la caracterización de los sujetos se combinan para crear imágenes que proporcionan una representación de las personas del Sur más o menos distanciada de la ciudadanía del Norte receptora de dichas fotografías.

\section{Resultados}

\subsection{Acción contra el Hambre}

En las doce portadas examinadas, las personas del Sur están presentes en diez de ellas (números 60, 62, 63, 64, 65, 66, 67, 68, 70 y 71) mientras que las del Norte son retratadas en dos (números 59 y 69 ).

Atendiendo a la primera de las dimensiones referentes a la relación interpersonal, en la mayor parte de las portadas de Acción contra el Hambre la distancia social es cercana con respecto al público lector (números 59, 60, 62, 63, 64, 66, 67, 68, 70 y 71). En el caso de las personas del Sur, se las ha retratado con un mayor distanciamiento en los números 65 y 70. En la portada del número 69, donde aparecen sujetos del Norte, también se los ha retratado en un plano lejano, pero el hecho de que lleven puesta una camiseta de la ONGD los aproxima, a nivel simbólico, a quien ve la revista: este último 
es alguien interesado/a por la labor de Acción contra el Hambre (presumiblemente un/a socio/a o colaborador/a) mientras que quienes aparecen en la imagen son participantes de una carrera organizada por la ONGD para recaudar fondos.

En cuanto a la relación social, en la mayoría de imágenes se ha empleado un ángulo que se ubica a la altura de los ojos de las personas representadas (números 60, $62,63,64,66,67,68,69,70$ y 71). Por tanto, se establece, simbólicamente, una relación de igualdad con quien las observa. No obstante, en la portada del número 59, se ha empleado un ángulo contrapicado, de manera que la persona representada queda un tanto engrandecida. En la portada del número 65, también se ha empleado el ángulo contrapicado. Éste ha servido para engrandecer a la persona retratada y para captar, en la misma imagen, el sol y el agua. Estos dos elementos son centrales en el titular que acompaña a la fotografía, 'Sol para hacer agua'. El titular y la imagen se refuerzan mutuamente para ilustrar un reportaje sobre el uso de la energía solar para extraer y bombear agua en Sahel.

El ángulo frontal solo se ha empleado en cuatro portadas (números 59, 66, 67 y 71). Así, aunque se haya ubicado el ángulo a la altura de los ojos en los números $60,62,63,64,68$ y 70, el público lector queda una tanto excluido del mundo de las personas representadas al haberse empleado un ángulo oblicuo para captarlas. En el número 69, aunque también se haya utilizado un ángulo oblicuo, el hecho de que las personas retratadas porten la camiseta de la ONGD las aproxima simbólicamente a quien observa la portada, como se ha explicado anteriormente.

Casi en la mitad de las portadas (números 63, 64, 65, 69 y 71), no existe interacción entre las personas que aparecen representadas en la imagen y quien las observa. La portada de la revista número 65 es la que establece una relación interpersonal menos estrecha entre quienes aparecen representados en ella y el público lector debido a que se ha empleado una distancia lejana, un ángulo oblicuo y no existe interacción. Sin embargo, en las portadas de los números 63 y 64, al usar un ángulo oblicuo y no existir interacción, también se crea un distanciamiento entre el universo de las personas representadas y quien mira la imagen, aunque queda mitigado por el hecho de que se ha empleado un plano cercano.

En cuanto a la caracterización de las actoras y los actores, llama la atención, en primer lugar, la ausencia de hombres del Sur: éstos solo están presentes en la portada del número 70. Quienes aparecen fundamentalmente en ellas son las niñas (números 64 y 68), los niños (números 63 y 66) y las mujeres acompañadas por algún menor (números 60, 65, 67 y 71). Sin embargo, en las portadas de los números 60 y 67, la presencia de las mujeres es parcial, ya que su figura aparece recortada y ni siquiera se puede ver su rostro. En ellas, el foco de atención se sitúa en los menores. Es destacable que, aunque tan solo hay dos portadas que muestran a personas del Norte, una de ellas está protagonizada por un hombre. Se trata de la portada del número 59, donde el actor José Sancho personifica lo que la ONGD ha dado en denominar la dictadura del hambre. El poder (la dictadura del hambre representada por el actor ataviado como Charlas Chaplin en la película El gran dictador) se identifica con un rostro masculino y del Norte.

Las personas del Sur han sido retratadas de manera pasiva en nueve de las portadas (números 60, 62, 63, 64, 66, 67, 68, 70 y 71). Tan solo en la portada 65 se muestra a una mujer realizando una acción. En cuanto a las portadas protagonizadas 
por personas del Norte, quienes aparecen en el número 69 sí se muestran de manera activa, pues participan en una carrera organizada por Acción contra el Hambre para recaudar fondos. Es decir, luchan activamente contra el hambre.

Han sido retratadas individualmente las personas del Sur que aparecen en las portadas de los números 62, 63, 64, 66 y 68. Aparecen en grupo los individuos fotografiados en las portadas de los números $60,65,67^{12}, 70$ y 71 . No obstante, los sujetos representados grupalmente aparecen diferenciados unos de otros salvo en las portadas de los números 65 , donde tan solo se pueden apreciar sus siluetas, y 70 , pues las personas que se muestran en esta fotografía se mimetizan con el entorno. En cuanto a las portadas en las que aparecen personas del Norte, en el número 59, se las presenta individualmente mientras que, en el número 69, se hace de manera grupal. En este último caso, las personas han sido retratadas de forma un tanto homogénea, pues visten de manera similar (sobre todo, destaca el hecho de que portan la camiseta de Acción contra el Hambre) y tienen una estatura parecida. Se genera la sensación de que muchas personas participaron en el evento organizado por la ONGD.

De manera específica, se han retratado a las personas del Sur que aparecen en las portadas de los números $60,62,63,64,66,67,68$ y 71. Las personas que se muestran en las portadas de los números 65 y 70 han sido representadas de manera genérica, atendiendo a un categorización cultural que las sitúa como colectivos que necesitan recibir algún tipo de ayuda (70) o ya la están recibiendo (65). No obstante, en cuanto a las personas del Sur retratadas de manera específica, es necesario precisar que en el dorso de la portada no se halla ningún pie de foto que explique quiénes son. Así, también se las sitúa como personas que necesitan recibir ayuda, puesto que son víctimas de alguna crisis o emergencia. Esta información se desprende de los titulares que acompañan a las fotografías donde destacan las palabras 'crisis' (números 62, 63, 66, 68 y 71), 'emergencia' (números 64 y 67) y 'refugiados' (números 62 y 71). En cambio, en el número 69, aunque las personas aparezcan de manera homogeneizada, se resalta de ellas su capacidad de movilización, participando, por ejemplo, en carreras solidarias.

En conclusión, las portadas de Acción contra el Hambre crean, a nivel simbólico, una relación interpersonal entre quienes las miran y las personas del Sur que aparecen en ellas próxima, gracias a recursos como planos cercanos o ángulos ubicados a la altura de los ojos. Sin embargo, el tipo de caracterización realizada refuerza, a nivel simbólico, una cierta separación entre un Sur sumergido en diferentes crisis y emergencias, pasivo y con rostro infantil y, en ocasiones, también femenino y un Norte que se encarga de ayudarlo o que ostenta el poder.

\subsection{Oxfam Intermón}

De las diez portadas de Oxfam Intermón, ocho están protagonizadas por personas del Sur (números 27, 28, 29, 30, 31, 32, 33 y 35) y dos por personas del Norte (números 26 y 34$)$.

En la mayoría de casos, las personas del Sur han sido retratadas con una distancia lejana (números 27, 28, 29, 32 y 35). Las portadas de los números 29 y 35 son un

${ }^{12}$ En 60 y 67, aunque en la fotografía aparezca más de una persona, el foco de atención se ha puesto en los menores. 
tanto singulares, pues, aunque se ha recogido a las figuras desde la cintura o desde los hombros, respectivamente, el efecto producido es de lejanía. En el primer caso, se debe a la aparición de un elemento delante del sujeto mientras que, en el segundo, el efecto de lejanía se produce porque la persona retratada aparece reflejada en un espejo. No obstante, el uso de planos lejanos ha permitido mostrar a los individuos en su contexto. En las portadas de los números 30, 31 y 33, se ha retratado a las personas de manera cercana.

En cuanto a las portadas en las que se muestran a personas del Norte, en el número 26, aparecen de manera cercana mientras que, en el número 34, lo hacen de manera lejana. En el primer caso, destacan los rostros particulares de quienes colaboran con Oxfam Intermón con los que se ha formado la palabra 'gracias'. Por el contrario, en el segundo caso, se muestra tanto a las personas como al contexto en el que se hallan. La fotografía fue tomada durante el viaje de colaboradores que la ONGD organizó en 2015 a Paraguay donde algunos/as de sus socios/as y colaboradores/as pudieron conocer programas y proyectos realizados por la entidad en el país.

El ángulo empleado tanto en las portadas en las que aparecen personas del Sur como del Norte se ha ubicado a la altura de los ojos. La mayor parte de las portadas han utilizado también ángulos frontales (números 26, 27, 28, 29, 31, 34 y 35). Las únicas portadas que han usado un ángulo oblicuo han sido las de los números 30, 32 y 33.

En las portadas, la interacción social está marcada por diversos recursos como, por ejemplo, la posición del cuerpo, la sonrisa o la mirada. En las dos portadas en que se muestra a personas del Norte (números 26 y 34), éstas interaccionan con el público lector a través de su sonrisa y su mirada, dirigidas hacia la cámara. En las portadas donde aparecen personas del Sur, existe interacción en las de los números 27, 28, 29, 30 y 31, en las dos primeras, a través de la sonrisa y la posición del cuerpo, y, en las tres últimas, a través de la mirada y la sonrisa. Así, aunque en las portadas de los números 27, 28 y 29 se hayan usado planos lejanos, gracias al empleo del ángulo frontal y a la interacción social se genera una gran sensación de proximidad. En el caso de la portada del número 30, a pesar de que se ha empleado un ángulo oblicuo, se crea proximidad con quien mira la imagen gracias al plano cercano y a la interacción que la protagonista de la imagen establece con el público lector. La portada del número 32 es la que marca una relación social más distanciada entre las personas retratadas y quien observa la imagen, debido al empleo de un plano lejano, un ángulo oblicuo y sin interacción por parte de las personas retratadas.

Las mujeres están presentes en todas las portadas en las que aparecen personas del Sur (números 27, 28, 29, 30, 31, 32, 33 y 35). Sin embargo, los hombres del Sur no han sido retratados en ninguna portada de manera que quedan excluidos de la representación. En cambio, en las portadas en las que se muestran a personas del Norte, han sido fotografiados tanto hombres como mujeres (números 26 y 34).

Las personas del Sur se muestran de manera activa en cuatro de las portadas analizadas (números 28, 29, 32 y 33). En otras cuatro, aparecen de manera pasiva, posando ante la cámara (números 27, 30, 31 y 35). No obstante, aunque no se haya retratado a estas personas desempeñando alguna activad, en las portadas de los números 27,30 y 31, las mujeres representadas dan una imagen positiva sobre sí mismas en la medida en que aparecen sonrientes y felices. En cuanto a las portadas en las que aparecen personas del Norte (números 26 y 34), éstas aparecen de manera 
pasiva. Sin embargo, dado que, en el número 26 , se les da las gracias por colaborar con la ONGD y, en el número 34, forman parte del viaje de colaboradores organizado por esta entidad, queda implícito que son personas que se movilizan ante los problemas del Sur.

En la mayor parte de las portadas donde se retrata a personas del Sur, se hace de manera individualizada y específica (números 27, 28, 29, 30, 31, 33, 35). Dicha individualidad es resaltada por el hecho de que, en el dorso de la portada, se halla un pie de foto donde aparece el nombre de los sujetos retratados así como su vinculación con las acciones realizadas por Oxfam Intermón. Se pone rostro humano concreto a las acciones de la organización. Esta circunstancia no se da en el caso de la portada del número 31, pues en el pie de foto se indica solamente que se trata de una mujer artesana que trabaja en un taller de comercio justo vinculado a la ONGD. No obstante, es destacable que, a pesar de que se haya resaltado la individualidad de las personas retratadas, se crea una suerte de categorización cultural con todas ellas como individuos beneficiarios de las acciones llevadas a cabo por la ONGD en el Sur.

Solo se ha hallado una portada en la que las personas del Sur han sido retratadas grupalmente (número 32). En la fotografía, se las presenta de manera homogeneizada, debido a que realizan la misma acción y tienen una misma posición corporal. Sin embargo, los colores de la ropa las diferencia un tanto. Asimismo, el pie de foto nombra directamente a una de ellas. No obstante, también se crea una categorización cultural, pues las mujeres desempeñan la misma labor y portan una vestimenta similar.

Las personas del Norte que aparecen en las portadas (números 26 y 34), a pesar de ser mostradas grupalmente, han sido representadas de manera diferenciada. Este hecho es más notable en la portada del número 26, pues la palabra 'gracias' se ha realizado con fotografías independientes que recogen a las personas en diversos contextos. A pesar de ello, también se las categoriza culturalmente, dado que se las representa como personas que colaboran con la ONGD. Solo la portada del número 34 tiene pie de foto y, en él, se refuerza dicha categorización. No aparece ninguna persona nombrada individualmente ${ }^{13}$.

En conclusión, Oxfam Intermón crea imágenes próximas al público lector al mismo tiempo que sitúa a las personas retratadas en su propio contexto. Aunque predominan los planos lejanos, el uso de recursos como, por ejemplo, los ángulos a la altura de los ojos o de elementos de interacción social (gestos amistosos, sonrisas y miradas dirigidas a la cámara) producen un efecto de cercanía. En el caso de las personas del Sur, la sensación de proximidad se refuerza por el hecho de que se las suele representar individualmente y su nombre y apellidos aparecen en los pies de foto. No obstante, también se las categoriza culturalmente, pues se destaca su vínculo con la ONGD, al igual que sucede con las portadas en las que se representa a personas del Norte.

\section{Conclusiones}

Las ONGD buscan movilizar a la ciudadanía del Norte para que contribuya a resolver las problemáticas del Sur, al que está estrechamente relacionado. En este trabajo, se han analizado las portadas de dos ONGD, Acción contra el Hambre y Oxfam

\footnotetext{
${ }^{13}$ En ambas revistas, a algunas de ellas se las identifica en las páginas interiores.
} 
Intermón, para conocer el tipo de relación que, a nivel simbólico, establecen entre la ciudadanía del Sur y del Norte en sus imágenes.

En el caso de Acción contra el Hambre, en la representación de las personas del Sur se han empleado elementos tanto que establecen una relación interpersonal estrecha, como puede ser, por ejemplo, el uso de planos cercanos (fundamentalmente primeros planos), miradas dirigidas hacia la cámara a través de las que se establece una interacción entre quien aparece en la imagen y quien la observa o ángulos situados a la altura de los ojos, como recursos que marcan un distanciamiento, como, por ejemplo, el uso de ángulos oblicuos, mayoritariamente, o la inexistencia de interacción en algunas de las portadas analizadas. Este distanciamiento queda reforzado por el hecho de que, aunque en muchas de las portadas, las personas aparecen representadas individualmente, no se dan datos sobre quiénes son. Su figura parece ilustrar únicamente la crisis o la emergencia sobre la que la ONGD va a hablar en las páginas interiores de la revista. De esta forma, se crea una suerte de categorización cultural de todos ellos donde se resalta su condición de víctimas pasivas que solo posan ante la cámara en espera de la ayuda. Dicha condición llama todavía más la atención cuando la portada aparece protagonizada por un/a niño/a, que, como se ha podido ver, es algo habitual en esta publicación.

En cuanto a Oxfam Intermón, el uso, principalmente, de planos lejanos (sobre todo planos generales) en la mayoría de portadas protagonizadas por personas del Sur no marca demasiado distanciamiento entre éstas y quienes observan la imagen, pues se emplean otros recursos (miradas, gestos y sonrisas, planos frontales) que permiten establecer una relación de cercanía entre el público lector y las personas retratadas. En este caso, además, en el pie de foto que acompaña la imagen de la portada se suele nombrar a la persona retratada. Estas fotografías sirven para poner rostro a las acciones que la ONGD realiza en el Sur. No obstante, también se establece una suerte de categorización cultural, al representar a estas personas como beneficiarias de las acciones de Oxfam Intermón.

En ambos casos, resalta la presencia de mujeres del Sur en las portadas examinadas y la ausencia de hombres. Es cierto que las informaciones que aparecen en las revistas de las ONGD están determinadas por el tipo de acciones que llevan a cabo y por los colectivos a los que las dirigen. Puesto que Acción contra el Hambre se dedica, fundamentalmente, a la ayuda humanitaria, resulta comprensible que trate sobre las distintas crisis y emergencias en las que trabaja en sus revistas. En el caso de Oxfam Intermón, dado que se dedica, principalmente, a la cooperación al desarrollo, puede ofrecer otro tipo de contenidos que se prestan a dar una imagen más diversa y rica sobre las personas del Sur. Sin embargo, en función de las portadas analizadas en este trabajo, se observa una tendencia a mostrar al Sur con rostro de mujer (e infantil, en el caso de Acción contra el Hambre) creando, a nivel simbólico, grupos de población vulnerables y necesitados de su ayuda. 


\section{Referencias bibliográficas}

BERNABÉ, J. (2007). El periodismo preventivo y las crisis humanitarias En I. Arcas (ed.), Medios de comunicación y organizaciones humanitarias en la respuesta a las crisis (pp. 17-21). Madrid: IECAH.

BOURDIEU, P. (1996). Sobre la televisión. Barcelona: Editorial Anagrama.

CIANCIO, A. (2007). Los medios de difusión y la acción humanitaria. Un nuevo marco para el debate. En I. Arcas (ed.), Medios de comunicación y organizaciones humanitarias en la respuesta a las crisis (pp. 9-15). Madrid: IECAH.

Coordinadora de ONG para el desarrollo-España (1989). Código de conducta sobre imágenes y mensajes a propósito del tercer mundo. Recuperado de

ESCOBAR, A. (2007). La invención del Tercer Mundo. Construcción y deconstrucción del desarrollo. Caracas: Fundación Editorial el perro y la rana.

ESCOBAR, A. (2010). Antropología y desarrollo. En G. J. Hernández (coord.), Antropología y desarrollo. Encuentros y desencuentros (pp. 29-58). La Habana: Centro Nacional de Superación para la Cultura.

ESCOBAR, A. (2012). Más allá del desarrollo: posdesarrollo y transiciones hacia el pluriverso. Revista de Antropología Social, 21, 23-62.

ESTEVA, G. (2000). Desarrollo. En A. Viola (comp.), Antropología del desarrollo. Teorías y estudios etnográficos en América Latina (pp. 67-92). Barcelona: Paidós Ibérica.

GÓMEZ GIL, C. (2005). Las ONG: De la apariencia a la realidad. Madrid: Los Libros de la Catarata.

GONZÁLEZ LUIS, H. (2006). Estrategias de comunicación en las ONG de Desarrollo. Departamentos, funciones e impacto en los medios. Madrid: CIDEALFundación Asistencia Técnica para el Desarrollo.

HIDALGO TENORIO, E. (2011). Critical Discourse Analysis. An Overview. Nordic Journal of English Studies, 10(1), 183-210.

KRESS, G. R., VAN LEEUWEN, T. (2006). Reading images: The grammar of visual design. Londres: Routledge.

LÓPEZ GARCÍA, J. (2005). Sentidos y efectos de la fotografía para la solidaridad. En C. Ortiz García, C. Sánchez-Carretero, y A. Gutiérrez (coords.). Manera de mirar. Lecturas antropológicas de la fotografía (pp. 83-108). Madrid: Consejo Superior de Investigaciones Científicas.

MARTÍN NIETO, R. (2009). El tercer mundo representado. La imagen como nido de estereotipos. Revista icono 14, 7(13),152-171.

MARTÍNEZ SÁNCHEZ, J. L. (1998). La imagen de las ONG. Para ir dimensionando el Tercer Sector. Madrid: IEPALA Editorial.

MOHANTY, C. T. (2008). Bajo los ojos de Occidente. Academia Feminista y discurso colonial. En L. Suárez y R. A. Hernández (eds.). Descolonizando el Feminismo: Teorías y Prácticas desde los Márgenes (pp. 117-163). Madrid: Cátedra.

NOS, E., IRANZO, A., y FARNÉ, A. (2012). La eficacia cultural de la comunicación de las ONGD: los discursos de los movimientos sociales actuales como revisión. CIC. Cuadernos de Información y Comunicación, 17, 209-237.

PICAS, J. (2001). El papel de las organizaciones no gubernamentales y la crisis del Desarrollo. Una crítica antropológica a las formas de cooperación. Tesis doctoral no 
publicada. Departament d'Antropologia Cultural i Història d'Amèrica i d'Àfrica, Universitat de Barcelona.

PICAS, J. (2003). Las ONG y la cultura de la solidaridad: la ética mínima de la acción humanitaria. Papers, 71, 65-76. Recuperado de http://ddd.uab.cat/pub/pape rs/02102862n71/02102862n71p65.pdf

SEVILLA GUZMÁN, E. (2000). Agroecología y desarrollo rural sustentable: una propuesta desde Latino América. Recuperado de http://geografiaposgrado.files. wordpress.com/2009/04/agroecologia-y-desarrollo-rural1.pdf

UNCETA, K. (2009). Desarrollo, subdesarrollo, maldesarrollo y postdesarrollo. Una mirada transdisciplinar sobre el debate y sus implicaciones. Carta latinoamericana. Contribuciones en desarrollo y sociedad en América Latina, 7, 1-34.

VAN DIJK, T. A. (1993). Principles of critical discourse analysis. Discourse and society, 4(2), 249-283.

VAN DIJK, T. A. (2009). Discurso y poder. Barcelona: Gedisa.

VAN LEEUWEN, T. (2008). Discourse and Practice. New tools for critical discourse analysis. Oxfordshire: Oxford University Press.

VIOLA, A. (Comp.) (2000). Antropología del desarrollo. Teorías y estudios etnográficos en América Latina. Barcelona: Paidós Ibérica.

WODAK, R., y MEYER, M. (2003). Métodos de análisis crítico del discurso. Barcelona: Gedisa.

WODAK, R. (2011). Critical Discourse Analysis. En K. Hyland, y B. Paltridge (eds.). The Continuum Companion to Discourse Analysis (pp. 38-53). India: Continuum. 